\title{
RETALHO DE SUBMUCOSA DE INTESTINO DELGADO AUTÓLOGO PARA AUMENTO DA CAPACIDADE DA BEXIGA: ESTUDO EXPERIMENTAL EM CÃES
}

\author{
SMALL INTESTINE SUBMUCOSA AS AN AUTOLOGOUS PATCH TO ENLARGE \\ BLADDER CAPACITY: EXPERIMENTAL STUDY ON DOGS
}

\author{
Fernando Hintz Greca, TCBC-PR ${ }^{1}$ \\ Maria de Lourdes Pessole Biondo-Simões, TCBC-PR ${ }^{2}$ \\ Eduardo Antônio Andrade dos Santos \\ Patrícia Carla Zanelatto-Gonçalves ${ }^{3}$ \\ Eduardo Wei Kin Chin ${ }^{3}$ \\ Sérgio Ossamu Ioshii ${ }^{4}$
}

\begin{abstract}
RESUMO: Objetivo: Os procedimentos disponíveis para correção de lesões do trato urinário não são livres de complicações. Recentemente, uma nova opção tem sido investigada: o uso da submucosa de intestino delgado (SIS). Constituída de uma matriz extracelular que não apresenta tendências à rejeição, a SIS é capaz de permitir o crescimento de vasos sangüíneos, participar de processos de diferenciação celular e de ser resistente contra o desenvolvimento de processos infecciosos. O objetivo deste estudo foi avaliar a histocompatibilidade de um enxerto autólogo de submucosa de intestino delgado (SIS), quando utilizado para a ampliação da bexiga urinária. Método: Utilizaram-se oito cães adultos, pesando entre 10 e $15 \mathrm{~kg}$. Realizou-se laparotomia mediana e enterectomia de um segmento de jejuno de $10 \mathrm{~cm}$, localizado a $20 \mathrm{~cm}$ da flexura duodeno-jejunal, seguida de anastomose terminoterminal. Desse segmento de intestino obteve-se, por dissecção, a camada submucosa. Após esvaziamento da bexiga por punção, fez-se uma incisão mediana de $3 \mathrm{~cm}$ em sua parede, compreendendo todas as camadas. Um segmento de $3 \times 2,5 \mathrm{~cm}$ de SIS foi fixado às bordas da incisão com sutura contínua, laçada de fio absorvível 3.0 de poliglecaprone-25. No $30^{\circ}$ dia de pós-operatório os animais foram submetidos à retirada da bexiga para estudo histopatológico. Resultados: Não se observou reação inflamatória aguda. Reação inflamatória crônica esteve presente com graus discreto e moderado. A infiltração fibroblástica foi moderada. A presença de células gigantes de corpo estranho foi mínima. A epitelização foi satisfatória, não sendo completa em apenas um dos oito implantes. Ocorreu incorporação predominante de fibras colágenas tipo III, cuja média correspondeu a 70,7\% do colágeno total. A reabsorção da mucosa foi moderada em 7/8 dos implantes. Conclusão: Os resultados indicam que ocorre regeneração da bexiga, quando é utilizada a submucosa de intestino delgado como substrato. A submucosa de intestino delgado autóloga pode ser uma alternativa viável na reconstrução da bexiga urinária.
\end{abstract}

Descritores: Submucosa de intestino delgado; Bexiga; Bioprótese.

\section{INTRODUÇÃO}

Neoplasias, traumatismos e lesões inflamatórias são algumas das afecções capazes de ocasionar graves danos ao sis- tema urinário que, ao deixarem seqüelas importantes, muitas vezes requerem intervenções cirúrgicas reconstrutivas.

Opções de substitutos para o trato urinário têm sido descritas, utilizando tanto materiais orgânicos quanto sin-

1. Professor Titular da Disciplina de Técnica Operatória e Cirurgia Experimental da PUCPR. Professor Adjunto da Disciplina de Técnica Cirúrgica e Cirurgia Experimental da UFPR. Doutor em Cirurgia Experimental pela UNIFESP-EPM.

2. Professora Titular da Disciplina de Técnica Operatória e Cirurgia Experimental da PUCPR. Professora Coordenadora da Disciplina de Técnica Cirúrgica e Cirurgia Experimental da UFPR. Doutora em Cirurgia Experimental pela UNIFESP-EPM.

3. Acadêmicos Monitores da Disciplina de Técnica Operatória e Cirurgia Experimental da PUCPR. Bolsistas do Programa PIBIC-PUCPR.

4. Doutor - Professor Adjunto da Disciplina de Patologia Experimental da PUCPR.

Recebido em 04/02/2002

Aceito para publicação em 14/05/2002

Trabalho realizado na Disciplina de Técnica Operatória e Cirurgia Experimental da Pontifícia Universidade Católica do Paraná (PUCPR) 
téticos. Os biomateriais são extremamente importantes no desenvolvimento de novas próteses de substituição de tecidos vivos. Eles garantem um substrato temporário para conduzir o crescimento e a organização do novo tecido, além de fornecerem sinais biológicos relacionados à adesão celular e síntese de fatores de crescimento.

Materiais não absorvíveis como politetrafluoretileno, polipropileno, esponja de polivinil, teflon e esponja de gelatina apresentaram complicações relacionadas ao desenvolvimento de reação tipo corpo-estranho ${ }^{1-3}$. O uso de resinas sintéticas e membranas de colágeno foi descrito em um número muito limitado de estudos experimentais ${ }^{4,5}$.

Experimentalmente, diversos enxertos biológicos foram preconizados para a cistoplastia de aumento, tais como retalho de músculo reto-femoral e membranas placentárias humanas, estas com baixa antigenicidade ${ }^{6,7}$. O pericárdio, testado como substituto da parede vesical, não permitiu regeneração muscular satisfatória ${ }^{8}$.

Segmentos do trato digestivo são freqüentemente utilizados em cirurgia urológica reconstrutora como substitutos ureterais, em ampliações ou substituições vesicais e, mais raramente, como substitutos uretrais. Vários segmentos do trato gastrointestinal têm sido usados na reconstrução do aparelho urinário. O estômago, o jejuno, o íleo e o cólon apresentam características próprias, com vantagens e desvantagens que devem ser muito bem avaliadas antes da correção.

O íleo, pela sua mobilidade e vascularização mais ou menos constante, representa hoje a principal opção para a ampliação vesical. Apesar da ileocistoplastia ter seu uso consagrado na prática cirúrgica, pode levar a uma série de complicações, como: infecção, formação de cálculos, distúrbios hidroeletrolíticos, perfuração, tumorogênese, anemia megaloblástica, hipolipidemia, ou ainda diarréia crônica, por interferir na reabsorção de sais biliares ${ }^{9}$.

$\mathrm{Na}$ verdade, o substituto ideal para segmentos do trato urinário ainda não foi encontrado. $\mathrm{O}$ melhor material seria aquele capaz de servir apenas como um molde para auxiliar a regeneração do tecido normal e ser reabsorvido antes do desenvolvimento de complicações locais, como infecção, formação de fístulas ou extrusão ${ }^{10}$.

Recentemente, o uso de matriz extracelular, como molde para reparo de tecidos moles, tem sido alvo de estudos experimentais em distintas áreas da medicina. A submucosa do intestino delgado (small intestine submu$\cos a$ - SIS), quando usada como substituto tissular, tem merecido especial atenção, devido à sua capacidade de reconstrução de estruturas, assemelhando-se às originais. A SIS não apresenta tendência à rejeição e infecção; tende a ser rapidamente absorvida, contrastando assim com as membranas de colágeno ou os materiais sintéticos, como o Dacron ou o politetrafluoroetileno.

A submucosa de intestino delgado é formada por proteínas estruturais e funcionais, como o colágeno, fibronectina, glicosaminoglicanos e fatores de crescimento ${ }^{11}$. Tem sido usada como enxerto bem-sucedido em pele, vasos, dura-máter, bexiga urinária, tendões e ossos nos mais diversos animais de experimentação, como rato, cachorro, gato, coelho e carneiro.
O objetivo deste estudo foi avaliar a histocompatibilidade de um enxerto autólogo de submucosa de intestino delgado (SIS), quando utilizado para a ampliação da bexiga urinária de cães.

\section{MÉTODO}

Este estudo obedeceu às normas de pesquisa com animais preconizadas pelo Colégio Brasileiro de Experimentação Animal (COBEA), instituição filiada ao International Council for Laboratory Animal Science.

Foram utilizados oito cães adultos, mestiços, de ambos os sexos, com peso entre 8 e $15 \mathrm{~kg}$, provenientes do Biotério da Pontifícia Universidade Católica do Paraná.

Os animais foram mantidos em condições de temperatura e luminosidade naturais e alimentados com ração canina de padrão comercial e água potável em regime livre. O jejum foi instituído nas 12 horas precedentes às operações.

Uma hora antes da operação, foram realizadas tricotomia e limpeza mecânica da região anterior do abdômen. A medicação pré-anestésica utilizada foi composta de sulfato de atropina $(0,05 \mathrm{mg} / \mathrm{kg})$ e clorpromazina $(0,5 \mathrm{mg} / \mathrm{kg})$ intramusculares, e a indução anestésica realizada com tiopental sódico-2,5\% (3mg/ $\mathrm{kg})$, endovenoso. A manutenção anestésica foi feita com citrato de fentanila $(0,05 \mathrm{mg} / \mathrm{kg})$ e midazolan $(0,2 \mathrm{mg} / \mathrm{kg})$ endovenosos.

A anti-sepsia da região operatória foi realizada com polivinilpirrolidona-1\% de iodo ativo. Na sequiência procedeu-se à laparotomia mediana supra e infra-umbilical de aproximadamente $15 \mathrm{~cm}$ de extensão.

Foi mobilizado um segmento de jejuno situado a 20 $\mathrm{cm}$ da flexura duodeno-jejunal, para ser então realizada enterectomia de $10 \mathrm{~cm}$ a partir desse ponto. Após a obtenção do segmento de jejuno, seu mesentério foi removido: em seguida procedeu-se à inversão do segmento de intestino, de modo que a mucosa ficasse voltada para fora. Essa foi então removida através de raspagem com bisturi, com a lâmina posicionada em sentido transversal ao maior eixo do intestino. Após ser desfeita a inversão do segmento intestinal, o extrato seromuscular foi removido pela mesma técnica (Figuras 1 e 2). O folheto de submucosa obtido foi colocado em solução de neomicina- $10 \%$, onde permaneceu por 30 minutos $^{12}$.

Com um cateter no 14 (Abocath ${ }^{\circledR}$ ), a bexiga foi puncionada em seu pólo superior, sendo promovido o seu esvaziamento. Com bisturi elétrico, procedeu-se à abertura da bexiga por meio de incisão mediana de $3 \mathrm{~cm}$ em sua face ântero-superior, até ser atingida a luz do órgão. Um segmento de submucosa de intestino delgado, medindo $3 \mathrm{~cm} \times 3 \mathrm{~cm}$ foi então implantado na parede da bexiga através de sutura contínua de fio de poliglecaprone-25 (Monocryl ${ }^{\circledR}$ ) no 3.0 (Figura 3).

Após a revisão da hemostasia e leve compressão manual da bexiga para certificar a impermeabilidade da sutura, procedeu-se à síntese da parede abdominal com sutura contínua de poliglactina 0 . A pele foi suturada com pontos separados de náilon 3.0. Convém salientar que não foi deixada sonda vesical em nenhum dos cães operados. 


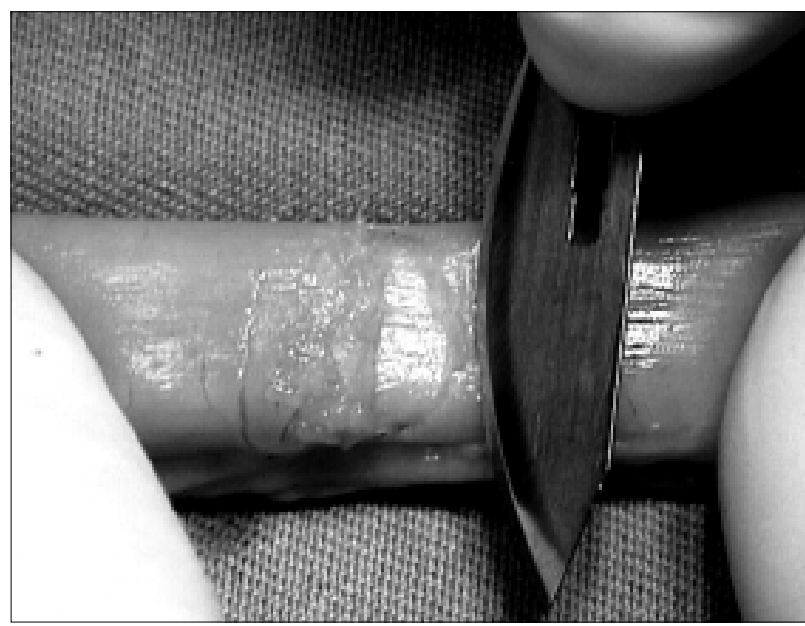

Figura 1 - Preparo da submucosa de intestino delgado. As camadas serosa e muscular estão sendo removidas através da raspagem com lâmina de bisturi (gentileza do Dr. Robinson Poffo).

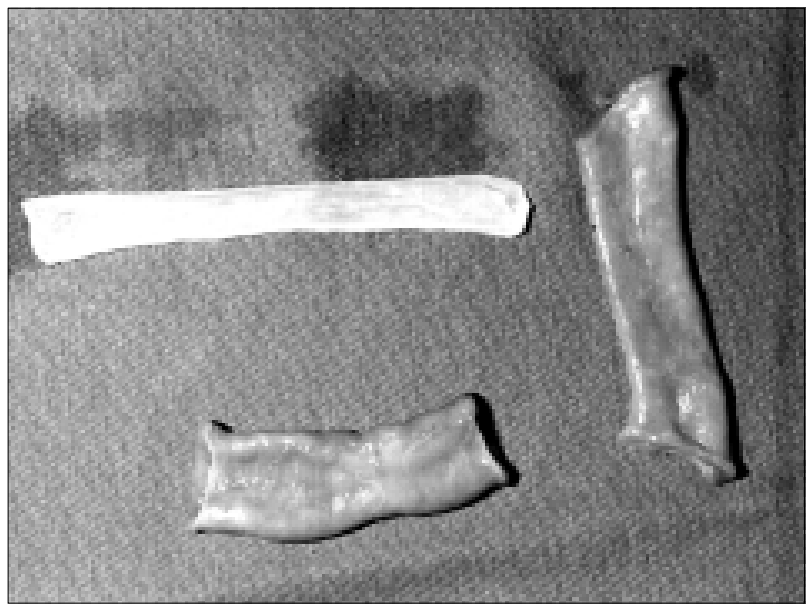

Figura 2 - As várias etapas do preparo da submucosa de intestino delgado. Inferiormente camada mucosa removida. À direita, as camadas serosa e muscular removidas. Acima, o aspecto final com a obtenção do extrato submucoso.

No trigésimo dia pós-operatório, os animais foram submetidos a uma segunda intervenção. Os cuidados pré-operatórios e a anestesia seguiram as mesmas normas adotadas na primeira cirurgia. $\mathrm{O}$ acesso aos implantes foi realizado pela cicatriz da primeira incisão. Após esvaziamento da bexiga, com a mesma técnica utilizada na primeira intervenção, o colo vesical foi ligado com fio de poliglactina 3.0. As aderências foram então desfeitas, os ligamentos perivesicais foram seccionados e uma incisão foi realizada no colo vesical, abaixo do nível da ligadura, de modo que a bexiga pudesse ser removida. Os animais foram por fim mortos com dose letal de droga depressora do sistema nervoso central.

Foi analisada a presença dos seguintes parâmetros na avaliação macroscópica: seroma; hematoma; absces-

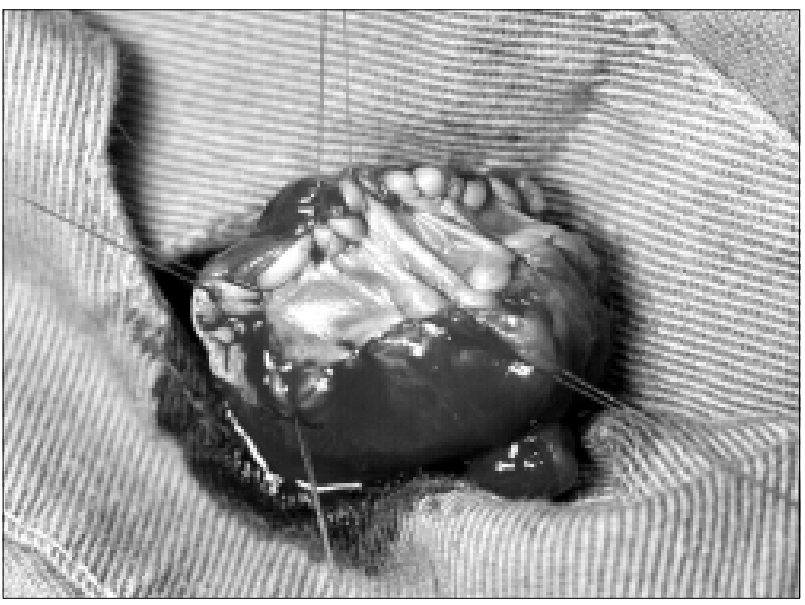

Figura 3 - Defeito de parede da bexiga reparado com um segmento de submucosa de intestino delgado (SIS) autóloga.

so; fístula; deiscência; aderências; litíase e não-incorporação do implante.

Um fragmento das peças cirúrgicas com o respectivo implante foi retirado e imerso em solução de formaldeído-5\% para o estudo microscópico. Os cortes histológicos, obtidos a partir dos fragmentos de tecido que continha o implante cirúrgico, foram corados com hematoxilinaeosina, para o estudo anatomopatológico e Sirius Red, para o estudo densitométrico do colágeno.

No estudo anatomopatológico os seguintes parâmetros foram analisados nos cortes corados com hematoxilina-eosina: reação inflamatória aguda; reação inflamatória crônica; presença de fibras musculares lisas reconstituídas e organizadas; presença de células gigantes; infiltração de fibroblastos; epitelização; neovascularização; e reabsorção da submucosa implantada.

No estudo densitométrico do colágeno, os cortes histológicos foram analisados através de microscopia óptica, em aumento de $400 \mathrm{X}$, com fonte de luz polarizada. As fibras de colágeno tipo I apresentam coloração vermelhoalaranjada e as fibras de colágeno III apresentam coloração esverdeada ${ }^{13}$.

As imagens foram captadas por uma câmera Sonyâ CCD 101, transmitidas a um microcomputador Pentium $®$, e analisadas por meio do aplicativo Optimasâ 6.2. Este programa possibilitou a determinação da quantidade percentual de colágeno tipo I, colágeno tipo III e colágeno total, representado pela soma dos dois anteriores.

\section{RESULTADOS}

No estudo macroscópico ocorreu incorporação perfeita de todos os implantes, tornando-os quase indistinguíveis das outras áreas da bexiga. A palpação cuidadosa demonstrou leve espessamento no local do implante. Foram observadas aderências discretas do peritônio parietal anterior. Não foram vistos seroma, hematoma, abscesso, litíase, fístula ou deiscência.

Os resultados do estudo anatomopatológico estão demonstrados na Tabela 1. Não foi observada reação in- 
flamatória aguda, ao passo que a crônica esteve presente entre os graus discreto e moderado. A infiltração fibroblástica foi moderada. A tolerância biológica do implante foi boa, uma vez que a presença de células gigantes foi mínima. A epitelização foi satisfatória, não sendo completa em apenas um dos oito implantes. A presença de fibras musculares lisas variou entre ausente e discreta, ainda sem características de organização e a reabsorção da submucosa implantada foi moderada.

Os dados do estudo densitométrico do colágeno estão descritos na Tabela 2. Ocorreu incorporação predominante de fibras colágenas tipo III, cuja média correspondeu a $70,7 \%$ do colágeno total.

\section{DISCUSSÃO}

Recentemente, pesquisas das mais diversas especialidades médicas vêm utilizando a submucosa de intestino delgado como substrato para a reconstrução cirúrgica de estruturas ou órgãos de vários sistemas. A SIS é constituída de uma matriz extracelular com boa tolerância biológica, não possuindo tendência à rejeição ${ }^{14}$. Apresenta baixos índices de infecção e, segundo alguns autores, até mesmo certas propriedades antibacterianas ${ }^{15,16}$. Também induz a angiogênese e ao proeminente crescimento de células de várias linhagens ${ }^{17,18}$.

$\mathrm{O}$ presente estudo demonstrou que um retalho de submucosa de intestino delgado pode ser excelente substrato para a regeneração vesical, quando implantado na bexiga de cães, permitindo assim o crescimento epitelial e muscular. $\mathrm{O}$ crescimento de um novo tecido contrátil sobre o molde de submucosa é preferível a uma cicatriz inerte, muitas vezes limitante no que diz respeito à contratilidade.

Em 1997, Pope et al. demonstraram que o crescimento de fibras musculares se inicia após duas semanas,

Tabela 1

Percentual de ocorrência dos parâmetros analisados no estudo anatomopatológico

\begin{tabular}{|c|c|c|c|c|}
\hline & Ausente & Discreta & Moderada & Acentuada \\
\hline Reação inflamatória aguda & $100 \%(8 / 8)$ & & & \\
\hline Reação inflamatória crônica & & $50 \%(4 / 8)$ & $50 \%(4 / 8)$ & \\
\hline Células gigantes & & $75 \%(7 / 8)$ & & \\
\hline Fibroblastos & & & $100 \%(8 / 8)$ & \\
\hline Neovascularização & & $50 \%(4 / 8)$ & $50 \%(4 / 8)$ & \\
\hline Epitelização & & & $12,5 \%(1 / 8)$ & $87,5 \%(7 / 8)$ \\
\hline Presença de fibras musculares lisas & $62,5 \%$ & $37,5 \%$ & & \\
\hline Organização de fibras musculares lisas & $100 \%$ & & & \\
\hline Reabsorção da submucosa & & $12,5 \%$ & $87,5 \%$ & \\
\hline
\end{tabular}

Tabela 2

Estudo densitométrico do colágeno. Comparação do percentual de incorporação de fibras colágenas tipos I e III ao enxerto de SIS

\begin{tabular}{c|c|c}
\hline Cão & $\begin{array}{c}\text { Colágeno maduro } \\
\text { (Tipo I) }\end{array}$ & $\begin{array}{c}\text { Colágeno imaturo } \\
\text { (Tipo II) }\end{array}$ \\
\hline Cão 1 & $29,9 \%$ & $70,1 \%$ \\
Cão 2 & $28,1 \%$ & $71,9 \%$ \\
Cão 3 & $29,9 \%$ & $70,1 \%$ \\
Cão 4 & $29,4 \%$ & $70,6 \%$ \\
Cão 5 & $30,9 \%$ & $69,1 \%$ \\
Cão 6 & $28,1 \%$ & $71,9 \%$ \\
Cão 7 & $32,6 \%$ & $67,4 \%$ \\
Cão 8 & $25,6 \%$ & $74,4 \%$ \\
\hline Média & $29,3 \%$ & $70,7 \%$ \\
\hline
\end{tabular}

data da migração inicial de miofibroblastos, e fibras musculares distintas estão presentes 10 semanas após o implante ${ }^{19}$. A regeneração de músculo liso pode ser consequiência de uma transmutação de células progenitoras de fibroblastos. A deposição de células mesenquimais derivadas da medula óssea deve também ser considerada. No presente estudo, foi observado que a presença de fibras musculares lisas ainda é muito discreta após 30 dias da data do implante.

Mesmo que a análise funcional da contratilidade não tenha sido escopo deste estudo, outros trabalhos demonstram que a contratilidade e a inervação da bexiga reparada com SIS são semelhantes às da bexiga normal ${ }^{20}$. Após a regeneração do tecido vesical, a complacência do implante é trinta vezes maior em relação à SIS nativa ${ }^{20}$. Estudo posterior em ratos verificou que as células musculares lisas regeneradas sobre um leito de SIS apresentam atividade contrátil in vivo ${ }^{21}$. A bexiga regenerada apresenta, além da atividade contrátil, receptores adrenérgicos e muscarínicos e inervação correspondente a eles ${ }^{22}$. 
A epitelização observada na quase totalidade $(87,5 \%)$ dos enxertos de submucosa intestinal não é surpresa, uma vez que vários estudos fazem referência à excelência da submucosa intestinal como substrato para crescimento de epitélio. O urotélio adjacente migra sobre a submucosa, visto que o tecido implantado tem características semelhantes às da membrana basal do epitélio vesical.

A neovascularização abundante que acompanha essas situações contribui para a aceleração de processo de reconstituição tecidual. Foi evidenciada a presença de fatores de crescimento angiogênicos, tais como fator de crescimento endotelial ${ }^{18}$ e fator de crescimento para fibroblas$\operatorname{tos}^{12}$.

Trabalhos prévios referem que a submucosa pode ser reabsorvida em dois meses. No presente estudo, foi verificado que em um mês ocorre reabsorção moderada da submucosa implantada. Segundo Badylak et al., após quatro semanas são observados apenas resquícios da SIS porcina, com neovascularização circunjacente extensa e epitelização contínua. Em oito semanas o implante já não é mais distinguível e a organização de fibras musculares é evidente ${ }^{12}$

Kropp et al. demonstraram que, após 12 semanas do implante, o enxerto de submucosa intestinal apresenta fibras colágenas maduras, tecido muscular desorganizado e epitelização completa ${ }^{23}$. Em quatro semanas foi observado, no presente estudo, uma incorporação predominante de colágeno tipo III, colágeno que depositado nas fases imaturas da cicatriz, que correspondeu a 70,7\% do colá- geno total. Talvez se o tempo de observação fosse maior, pudesse ser verificada uma quantidade significativamente maior de fibras tipo I, colágeno encontrado nas cicatrizes maduras.

Neste primeiro trabalho foi utilizada a SIS autóloga com o objetivo de diminuir o número de variáveis, bem como de adquirir experiência com o método proposto.

Apesar de não ter sido utilizada a sondagem vesical no pós-operatório, não foram evidenciadas fístulas, deiscências ou abscessos. Aderências com o peritônio parietal anterior foram observadas na quase totalidade dos casos.

A regeneração e a cicatrização são linhas de pesquisa desenvolvidas pela Disciplina de Técnica Operatória e Cirurgia Experimental da PUCPR e a utilização da submucosa de intestino delgado como substrato para regeneração tissular tem motivado o início de outros estudos em órgãos e estruturas tão distintas como esôfago, parede abdominal, intestino delgado, pele e tendões, com resultados muito animadores e promissores. Recentemente a equipe iniciou estudos com submucosa porcina para implante em cães, ratos e coelhos, com resultados iniciais muito favoráveis que, em futuro próximo, serão relatados.

Pode-se concluir com este trabalho que:

1. Ocorre regeneração da bexiga, quando é utilizada a submucosa de intestino delgado autóloga como substrato.

2. A submucosa de intestino delgado autóloga pode ser uma alternativa viável na reconstrução do trato urinário.

\begin{abstract}
Background: Many materials, including organic and synthetic prosthesis, have been described as substitutes of the genitourinary tract. The most commonly used is the ileum, which has many advantages, as easy mobilization and regular vascular pattern. However, the ideal substitute for urinary tract has not been found yet. Ileocystoplasty is not a harmless procedure, and so, investigations are constantly being made to find new substitutes. Small intestinal submucosa (SIS) is an extracelular matrix that can be used as a reabsorbable scaffold for tissue engineering. It allows blood vessels ingrowth, epithelial and connective cells proliferation, induces growing factors production and acquires macro and microscopic characteristics similar to the native tissue. In the urinary tract, previous experimental studies have demonstrated that SIS promotes bladder regeneration. The aim of the present study was to evaluate the biocompatibility of an autologous SIS implant used for bladder augmentation. Method: Eight mongrel dogs, weighing between 8 and $15 \mathrm{~kg}$, were prepared for surgery under general anesthesia. A $3 \mathrm{~cm}$ full-thickness midline cystotomy was performed, followed by immediate augmentation with autologous small intestine submucosa patch graft. On the $30^{\text {th }}$ post-operative day, the animals were re-operated and a fragment of the urinary bladder wall including its patch was removed for histopathogical study. Results: All implants were well incorporated. Macroscopically, SIS could not be distinguished from the native bladder tissue. Mild adherences occurred on the anterior parietal peritoneum. No other macroscopic complications were found. Acute inflammatory response was absent, and chronic inflammatory cells were seen in mild degree. Foreign body reaction was not present, implying satisfactory biological acceptation of the SIS patch graft. Epithelialization was complete in 7/8 implants. Fibroblastic proliferation was moderate. The densitometry of collagen revealed a greater amount of collagen III. Submucosa patch absorption was moderate in most cases. Conclusion: We concluded that autologous small intestine submucosa promotes bladder tissue regeneration. Small intestinal submucosa can represent a new option in urinary tract reconstruction.
\end{abstract}

Key Words: Small intestine submucosa; Bladder; Bioprothesis. 


\section{REFERÊNCIAS}

1. Bohne AW, Urwiller KL. Experience with urinary bladder regeneration. J Urol 1957; 77: 725.

2. Kudish HG. The use of polyvinyl sponge for experimental cystoplasty. J Urol 1957; 78: 232.

3. Swinney J, Tomlinson BE, Walder DN. Urinary tract substitution. Br J Urol 1961; 62: 26-31.

4. Taguchi H, Ishizuka E, Saito K. Cystoplasty by regeneration of the bladder. J Urol 1977; 118(5): 752-756.

5. Gorham S, McCafferty I, Baraza R, Scott R. Preliminary development of a collagen membrane for use in urological surgery. Urol Res 1984; 12(6): 295-299.

6. Messing EM, Dibbell DG, Belzer FO. Bilateral rectus femoris pedicle flaps for detrusor augmentation in the prune belly syndrome. J Urol 1985; 134(6): 12021205.

7. Fishman IJ, Flores FN, Scott B et al. Use of fresh placental membranes for bladder reconstruction. J Urol 1987; 138: 1291.

8. Kambic H, Kay R, Chen JF et al. Biodegradable pericardial implants for bladder augmentation: a 2.5-year study in dogs. J Urol 1992; 148: 539-43.

9. McDougal WS. Use of intestinal segments in the urinary tract. In: Campbell MF. Campbell's urology. 6ed. Philadelphia: WB Sounders; 1992. p 2595-2629.

10. Cheng E, Rento R, Grayhack JT et al. Reversed seromuscular flaps in the urinary tract in dogs. J Urol 1994; 152: 2252-7.

11. Mcpherson TB, Badylak SF. Characterization of fibronectin in SIS. SIS Symp 1998; 88.

12. Badylak Sf, Lantz GC, Coffey AC, Geddes LA. Small intestinal submucosa as a large-diameter arterial graft in the dog. J Surg Res 1989; 47: 74-78.

13. Junqueira LCU, Cossermelli W, Brentani RR. Differential stain of collagen type I, II and III by syrius red and polarization microscopy. Arch Histol Jpn 1978; 41: 276-274.

14. Mcpherson TB, Badylak SF, Hogenesch H et al. Effect of local response to xenogeneic ECM on systemic immunity. SIS Symp 1998; 34.

15. Record RD, Mcpherson TB, Liang HA et al. Bacterial adherence to SIS and other biomaterials. SIS Symp 1998; 39.

16. Sarikaya A, Record RD, Badylak SF, Ladisch MR. Antibacterial properties of SIS. SIS Symp 1998; 40.

17. Liang HA, Record RD, Hodde JP, Badylak SF. Human microvascular endothelial cell adhesion to small intestinal submucosa. SIS Symp 1998; 91.

18. Hodde JP, Mcpherson TB, Savaiano JK, Badylak SF. Vascular endothelial growth factor (VEGF) in SIS. SIS Symp 1998; 92.
19. Pope JC, Davis MM, Smith ER Jr et al. The ontogeny of canine small intestinal submucosa regenerated bladder J Urol 1997; 158(3 Pt 2): 1105-1110.

20. Kropp BP, Sawyer BD, Shannon HE et al. Characterization of small intestinal submucosa regenerated canine detrusor: assessment of reinnervation, in vitro compliance and contractility. J Urol 1996; 156(2 Pt 2): 599607.

21. Zhang Y, Poff C, Bane BL, Kropp BP. Epithelial-stromal interactions: Is regenerating epithelium required for smooth muscle regeneration ? SIS Symp 1998; 12.

22. Vaught JD, Kropp BP, Sawyer BD et al. Detrusor regeneration in the rat using porcine small intestinal submucosal graft: functional innervation and receptor expression J Urol 1996; 155(1): 374-378.

23. Kropp BP, Eppley BL, Prevel CD et al. Experimental assessment of small intestinal submucosa as a bladder wall substitute. Urology 1995; 46 (3): 396-400.

Endereço para correspondência:

Maria de Lourdes Pessole Biondo-Simões

Rua Ari José Valle, 1987, Santa Felicidade 82030-000 - Curitiba-PR

e-mail: biondo@avalon.sul.com.br 